\title{
Modification of the fatty acid composition of dietary oils and fats on incorporation into chylomicrons and chylomicron remnants
}

\author{
BY MARC S. LAMBERT, KATHLEEN M. BOTHAM* AND PETER A. MAYES \\ Division of Biochemistry, Department of Veterinary Basic Sciences, Royal Veterinary College, \\ University of London, London NWI OTU
}

(Received 31 May 1995 - Revised 20 December 1995-Accepted 23 January 1996)

\begin{abstract}
Possible changes in the fatty acid composition of dietary fats and oils which might occur during digestion, absorption and formation of chylomicrons and chylomicron remnants were investigated. Chylomicrons were collected from the thoracic duct of rats tube-fed with olive, maize, palm or fish oil or butter fat, and their fatty acid composition was determined and compared with that of their parent lipids. In turn, these lipoproteins were converted to chylomicron remnants in functionally hepatectomized rats and their composition re-determined. The predominant fatty acids in each of the oils and fats also predominated in their respective chylomicrons, but their proportions were reduced during the processes leading to their formation. Endogenous contributions of linoleic, eicosapentaenoic, and docosahexaenoic acids were particularly noted when these fatty acids were not well-represented in the original oils and fats, suggesting that they may be obligatory constituents in the formation of chylomicrons. The conversion of chylomicrons to remnants further attenuated the extremes in fatty acid composition of the dietary oils and fats. These results indicate that following an acute intake of oil or fat, the resulting chylomicrons and chylomicron remnants presented to the tissues contain a more balanced distribution of saturated, mono- and polyunsaturated fatty acids than the oils and fats from which they were derived.
\end{abstract}

Fatty acid composition: Dietary fat: Chylomicrons: Chylomicron remnants

Numerous investigations have been made of the relationship between the degree of saturation of dietary fatty acids and the concentration of plasma cholesterol. The main conclusions drawn from these studies are that dietary saturated fatty acids, particularly palmitate, increase plasma cholesterol concentrations, mainly in low-density lipoproteins (LDL), whereas $n-6$ polyunsaturated fatty acids have the opposite effect (Kinsell et al. 1952; Ahrens et al. 1957; Keys et al. 1965). More recently, oleic acid has been reported to be hypocholesterolaemic (Mattson \& Grundy, 1985), and long-chain n-3 polyunsaturated fatty acids have been found to have variable effects on plasma cholesterol, but to reduce triacylglycerol concentrations, particularly in very-low-density lipoproteins (VLDL; Harris et al. 1983). Many of these observations preceded the present detailed understanding of lipoprotein metabolism, so there has been little consideration of the pattern of incorporation of dietary fatty acids into the triacylglycerol-rich chylomicrons and their remnants.

Chylomicrons are formed in enterocytes as a consequence of the uptake of dietary fatty acids and cholesterol, and enter the bloodstream via the lymphatic system. In the circulation, chylomicron triacylglycerol is rapidly hydrolysed by the enzyme lipoprotein lipase $(E C 3.1 .1 .34)$ located on the endothelial surface of capillaries in extrahepatic

\footnotetext{
* For reprints.
} 
tissues, resulting in the delivery of free fatty acids to the tissues and the formation of chylomicron remnant lipoproteins (Redgrave, 1970). Chylomicron remnants are relatively enriched in esterified cholesterol and have been shown to be atherogenic in experimental animals (Zilversmit, 1979; Melchior et al. 1981), and in human subjects (Karpe et al. 1994). Ultimately, remnants are removed from the circulation by the liver via a receptor specific for apolipoprotein E (Mahley et al. 1989).

Since the type of fatty acid in the diet affects cholesterol metabolism and, therefore, can be considered to be involved in the development of atherosclerosis, it is important to ascertain the extent to which the composition of chylomicrons and their remnants reflects the composition of the dietary lipid from which they are derived. In the present investigation the fatty acid composition of chylomicrons resulting from the ingestion of olive, maize, palm or fish oil, or butter fat in rats was analysed and, on the one hand, compared with the composition of the oils or fat from which they were derived, and on the other, with the composition of their resulting chylomicron remnants, the particles that are ultimately the vehicles for uptake into the liver of dietary fatty acids and cholesterol.

\section{MATERIALS AND METHODS}

\section{Animals, diets and chemicals}

Male Wistar rats $(350-370 \mathrm{~g})$ were used for the preparation of chylomicrons and chylomicron remnants. There were no significant differences in body weight between any of the experimental groups. Before use the rats were fed on a standard commercial rat pellet (low-fat- diet and kept under constant day length $(12 \mathrm{~h})$ and temperature $\left(25^{\circ}\right)$. The diet contained soyabean oil as the principal lipid source $(2.5 \%$ of the total energy intake), with oleic and linoleic acids representing half of the total fatty acids present, and the remainder being associated with small amounts of other saturated, mono- and polyunsaturated fatty acids. Sodium pentobarbital and menhaden fish oil were obtained from Sigma Chemical Co., Poole, Dorset. Palm oil was obtained from Rhone Poulenc, Manchester. Olive oil, maize oil and butter were obtained from domestic suppliers. All other chemicals were obtained from BDH, Dagenham, Essex and Fisons, Loughborough, Leics.

\section{Preparation of chylomicrons and chylomicron remnants}

Chylomicrons were prepared according to the methods described by Bollman et al. (1948). Briefly, on the morning of the experiment, one rat was tube-fed with either olive, maize, palm or fish oil, or filtered butter fat $(0.5 \mathrm{ml})$; each oil or fat was supplemented with $\alpha$ tocopherol $(4 \mathrm{mg} / \mathrm{ml})$ as an antioxidant. After approximately $1 \mathrm{~h}$ the rat was anaesthetized with sodium pentobarbital $(60 \mathrm{mg} / \mathrm{kg}$ body weight i.p.), the abdominal cavity was opened and the thoracic duct was cannulated with polyethylene tubing (external diameter $1.52 \mathrm{~mm}$ ) and secured with a ligature. When the chyle was flowing satisfactorily, a further $0.5 \mathrm{ml}$ of the same oil or fat fed initially was injected through the wall of the pyloric region of the stomach. The abdominal wall was sutured and the rat placed in a restraining cage. The animal was allowed to recover, during which time it had access to saline $(9 \mathrm{~g} \mathrm{NaCl} / 1)$ for $5 \mathrm{~h}$, and water overnight. Over this period the chyle was collected into a tube containing ampicillin $(0.05 \mathrm{mg})$. Following collection, $2 \mathrm{ml}$ portions of the chyle were layered under $\mathrm{NaCl}$ (density $1.006 \mathrm{~g} / \mathrm{ml}$ ) in $6.5 \mathrm{ml}$ polyallomer tubes and ultracentrifuged at $20000 \mathrm{rev}$.) $\min$ for $21 \mathrm{~min}\left(6 \times 10^{5} \mathrm{~g} \cdot \mathrm{min}\right)$ in a fixed-angle rotor at a temperature of $12^{\circ}$. This allowed large chylomicrons (diameter $>100 \mathrm{~nm}$ ) free from intestinal VLDL to float to the tops of the tubes and they were then removed by slicing the top 10-15 mm using a Beckman tube slicer.

Chylomicron remnants were prepared in vivo from the chylomicrons, using methods 
Table 1. Fatty acid composition of palm oil, and of the chylomicrons and chylomicron remnants derived from it $(\mathrm{g} / 100 \mathrm{~g}$ total fatty acids $) \$$

(Mean values with their standard errors for three independent preparations)

\begin{tabular}{|c|c|c|c|c|c|c|}
\hline \multirow[b]{3}{*}{ Fatty acid } & \multicolumn{6}{|c|}{ Palm oil } \\
\hline & \multicolumn{2}{|c|}{ Oil } & \multicolumn{2}{|c|}{ Chylomicrons } & \multicolumn{2}{|c|}{ Chylomicron remnants } \\
\hline & Mean & $\mathrm{SE}$ & Mean & $\mathrm{SE}$ & Mean & $\mathrm{SE}$ \\
\hline $10: 0$ & ND & & ND & & ND & \\
\hline $12: 0$ & ND & & ND & & ND & \\
\hline $14: 0$ & 0.97 & 0.01 & $1 \cdot 10$ & 0.05 & $1 \cdot 01$ & 0.04 \\
\hline $16: 0$ & $44 \cdot 00$ & 0.22 & $32 \cdot 61 * * *$ & $1 \cdot 22$ & $29 \cdot 12$ & 0.91 \\
\hline $16: 1$ & $1 \cdot 87$ & 0.02 & $0.99 * * *$ & 0.12 & $3.02+1 \dagger$ & $0 \cdot 18$ \\
\hline $18: 0$ & $4 \cdot 31$ & 0.03 & $4 \cdot 67$ & $0 \cdot 22$ & 499 & 0.23 \\
\hline $18: 1$ & 38.66 & 0.25 & 36.86 & 1.00 & 33.86 & 0.63 \\
\hline $18: 2$ & 9.98 & 0.05 & $16 \cdot 91^{* *}$ & 1.42 & $18 \cdot 14$ & $1 \cdot 50$ \\
\hline $18: 3$ & 0.23 & 0.01 & $0.62^{*}$ & $0 \cdot 12$ & 0.41 & 0.07 \\
\hline $20: 5$ & ND & & $0.48^{* *}$ & $0 \cdot 10$ & 0.74 & 0.04 \\
\hline $22: 6$ & ND & & $1 \cdot 34 * *$ & $0 \cdot 20$ & $2 \cdot 50 \dagger$ & 0.36 \\
\hline Minor unidentified & ND & & $4 \cdot 42$ & $0 \cdot 16$ & $6 \cdot 21 \dagger$ & 0.35 \\
\hline \multicolumn{7}{|l|}{ Total identified } \\
\hline Saturated & $49 \cdot 28$ & 0.29 & $38 \cdot 38 * *$ & 1.44 & $35 \cdot 12$ & $1 \cdot 11$ \\
\hline Monounsaturated & $40 \cdot 53$ & 0.28 & $37.85^{*}$ & 0.93 & $36 \cdot 88$ & 0.46 \\
\hline Polyunsaturated & $10 \cdot 19$ & 0.06 & $19 \cdot 35^{* *}$ & 1.27 & 21.79 & 1.81 \\
\hline $\mathbf{P}: \mathbf{S}$ & 0.21 & & 0.50 & & 0.62 & \\
\hline
\end{tabular}

ND, not detected ( $<0.2 \mathrm{~g} / 100 \mathrm{~g}$ total fatty acids); P:S, polyunsaturated: saturated fatty acid ratio. Mean values were significantly different from those for palm oil, ${ }^{*} P<0.05,{ }^{* *} P<0.01,{ }^{* * *} P<0.001$. Mean values were significantly different from those for chylomicrons, $\dagger P<0.05, \dagger \dagger \dagger P<0.001$. $\ddagger$ For details of experimental procedures, see pp. 436439.

based on those of Redgrave (1970). These experiments were performed during the afternoon following chyle collection, to ensure that the rats used were in a post-absorptive state. Rats (four to six animals per chylomicron preparation) were anaesthetized as described previously, and functionally hepatectomized by ligation of the coeliac artery, the anterior mesenteric artery, and the hepatic portal vein. Chylomicrons (containing $30-40 \mu \mathrm{mol}$ triacylglycerol) and $50 \mathrm{mg}$ glucose in $2 \mathrm{ml} 9 \mathrm{~g} \mathrm{NaCl} / 1$ were injected into the left ileolumbar vein. After $45 \mathrm{~min}$ the rats were exsanguinated via the abdominal aorta, while a $\mathrm{NaCl}$ solution $(9 \mathrm{~g} / 1)$ containing $10 \mathrm{~g}$ bovine serum albumin/l was infused into the right ileolumbar vein. The blood removed was allowed to clot for $15 \mathrm{~min}$ at $37^{\circ}$, and the serum was separated by centrifugation at $3000 \mathrm{~g}$ for $15 \mathrm{~min}$ at $12^{\circ}$. The rat serum was layered $(4-5 \mathrm{ml} /$ tube $)$ under $\mathrm{NaCl}(1.006 \mathrm{~g} / \mathrm{ml})$ in $6.5 \mathrm{ml}$ polyallomer tubes and ultracentrifuged for $6 \times 10^{7} \mathrm{~g}$. min at $12^{\circ}$. The top fraction $(1 \mathrm{ml})$ from this centrifugation was harvested by tube slicing and further purified by layering $(2 \mathrm{ml})$ under $\mathrm{NaCl}(1.006 \mathrm{~g} / \mathrm{ml})$ and ultracentrifugation for $3.2 \times 10^{7} \mathrm{~g}$. min at $12^{\circ}$. The top fraction $(1 \mathrm{ml} / \mathrm{tube})$ was isolated and used as the chylomicron remnant preparation.

The rats employed for the preparation of chylomicron remnants were in a postabsorptive state to ensure that their serum concentrations of VLDL and intermediatedensity lipoproteins (IDL) were minimal, and two centrifugation steps were used to reduce further the possibility of contamination. The absence of VLDL and IDL from the remnant preparations was confirmed by SDS-PAGE, which demonstrated the presence of apolipoproteins B-48 and E and the lack of apolipoprotein-B100 (results not shown). 
Table 2. Fatty acid composition of butter fat, and of the chylomicrons and chylomicron remnants derived from it $(\mathrm{g} / 100 \mathrm{~g}$ total fatty acids $) \$$

(Mean values with their standard errors for three independent preparations)

\begin{tabular}{|c|c|c|c|c|c|c|}
\hline \multirow[b]{3}{*}{ Fatty acid } & \multicolumn{6}{|c|}{ Butter fat } \\
\hline & \multicolumn{2}{|c|}{ Fat } & \multicolumn{2}{|c|}{ Chylomicrons } & \multicolumn{2}{|c|}{ Chylomicron remnants } \\
\hline & Mean & $\mathrm{SE}$ & Mean & $\mathrm{SE}$ & Mean & $\mathrm{SE}$ \\
\hline $10: 0$ & $2 \cdot 54$ & 0.09 & $0.92^{* * *}$ & 0.11 & ND+t+ & \\
\hline $12: 0$ & $4 \cdot 39$ & 0.02 & $3 \cdot 80$ & 0.42 & ND†t† & \\
\hline $14: 0$ & $14 \cdot 13$ & $0 \cdot 10$ & $10 \cdot 31^{*}$ & 0.95 & $4 \cdot 84 \uparrow$ & 1.51 \\
\hline $16: 0$ & $35 \cdot 10$ & 0.27 & $24 \cdot 66^{* * *}$ & $0 \cdot 79$ & 27.98 & 1.66 \\
\hline $16: 1$ & 1.87 & 0.02 & $2 \cdot 87^{* *}$ & $0 \cdot 14$ & 3.59 & 0.72 \\
\hline $18: 0$ & $12 \cdot 40$ & 0.07 & $6 \cdot 61^{* * *}$ & $0 \cdot 24$ & $8 \cdot 30 \dagger$ & $0 \cdot 30$ \\
\hline $18: 1$ & 16.56 & 0.12 & $19 \cdot 67^{* *}$ & 0.66 & $21 \cdot 11$ & 0.53 \\
\hline $18: 2$ & $1 \cdot 83$ & 0.03 & $17 \cdot 02^{* * *}$ & $2 \cdot 49$ & $16 \cdot 51$ & 1.43 \\
\hline $18: 3$ & 0.42 & 0.03 & 1.95 & 0.09 & $0.79+\dagger$ & $0 \cdot 22$ \\
\hline $20: 5$ & ND & & 0.92 & $0-22$ & 1.44 & 0.65 \\
\hline $22: 6$ & ND & & 1.98 & $0 \cdot 30$ & $2 \cdot 64$ & $0 \cdot 26$ \\
\hline Minor unidentified & $10 \cdot 76$ & 0.90 & $9 \cdot 29$ & $0 \cdot 35$ & $12-80 \dagger \dagger$ & 0.53 \\
\hline \multicolumn{7}{|l|}{ Total identified } \\
\hline Saturated & $68 \cdot 56$ & 0.41 & $46 \cdot 30^{* * *}$ & $2 \cdot 11$ & $41 \cdot 12$ & $3 \cdot 31$ \\
\hline Monounsaturated & 18.43 & $0 \cdot 14$ & $22 \cdot 54 * *$ & 0.77 & $24 \cdot 70$ & $0-86$ \\
\hline Polyunsaturated & 2.25 & 0.06 & $21 \cdot 87^{* * *}$ & 1.79 & $21 \cdot 38$ & $2 \cdot 95$ \\
\hline$P: S$ & 0.03 & & 0.47 & & $0 \cdot 52$ & \\
\hline
\end{tabular}

$\mathrm{ND}$, not detected $(<0.2 \mathrm{~g} / 100 \mathrm{~g}$ total fatty acids); $\mathrm{P}: \mathrm{S}$, polyunsaturated : saturated fatty acid ratio.

Mean values were significantly different from those for butter fat, $* P<0.05, * * P<0.01,{ }^{* * *} P<0.001$.

Mean values were significantly different from those for chylomicrons, $\uparrow P<0.05,+\dagger P<0.01,+\dagger \dagger P<0.001$. $\ddagger$ For details of experimental procedures, see pp. $436-439$.

\section{Determination of fatty acid composition}

Fatty acid methyl esters were prepared from the parent oils and fats and each of the chylomicron and remnant preparations using the transmethylation method of Morrison \& Smith (1964). For the parent oils and fats the results represent the means from three samples, and for the chylomicrons and chylomicron remnants they are the means from three independent preparations. Briefly, the lipids were extracted from each sample using a minimum of 20 volumes of chloroform-methanol $(2: 1, \mathrm{v} / \mathrm{v})$, and partitioned with 0.4 volumes of $0.03 \mathrm{M}-\mathrm{HCl}$. Following the removal of the aqueous phase, the chloroform layers were dried under $\mathrm{N}_{2}$, the lipid samples were hydrolysed, and the resulting fatty acids were methylated using $1 \mathrm{ml}$ boron trifluoride-methanol-methanol-hexane $(35: 30: 35$, by vol.) at $100^{\circ}$ for 45-60 min. When cool, the fatty acid methyl esters were extracted by adding 2 volumes of hexane, then 1 volume of distilled water, shaking briefly, and centrifuging at $3000 \mathrm{~g}$ for $15 \mathrm{~min}$ at $12^{\circ}$. The fatty acid methyl esters from the hexane layer were separated by GC (Shimadzu GC 9A, Shimadzu Seizakusho Co., Kyoto, Japan) using a glass column $(1.5 \mathrm{~m} \times 2 \mathrm{~mm}$ ) packed with GP $3 \%$ SP-2310/2\% SP-2300 on $100 / 120$ chromosorb WAW (Supelco UK, Poole, Dorset), and using a temperature programme of $190^{\circ}$ for $2 \mathrm{~min}$, increasing from $190-220^{\circ}$ at a rate of $2^{\circ} / \mathrm{min}$, and then maintained at $220^{\circ}$ for a further $20 \mathrm{~min}$. Peaks were identified and quantified using known fatty acid methyl ester standards (Supelco UK), and the areas under the peaks were integrated by means of a Shimadzu CR2AX electronic data processor. The results are expressed as a percentage of the total fatty acid mass measured. The method for fatty acid methylation (Morrison \& Smith, 1964) 
Table 3. Fatty acid composition of maize oil, and of the chylomicrons and chylomicron remnants derived from it $(\mathrm{g} / 100 \mathrm{~g}$ total fatty acids $) \$$

(Mean values with their standard errors for three independent preparations)

\begin{tabular}{|c|c|c|c|c|c|c|}
\hline \multirow[b]{3}{*}{ Fatty acid } & \multicolumn{6}{|c|}{ Maize oil } \\
\hline & \multicolumn{2}{|c|}{ Oil } & \multicolumn{2}{|c|}{ Chylomicrons } & \multicolumn{2}{|c|}{ Chylomicron remnants } \\
\hline & Mean & SE & Mean & SE & Mean & SE \\
\hline $10: 0$ & ND & & ND & & ND & \\
\hline $12: 0$ & ND & & ND & & ND & \\
\hline $14: 0$ & ND & & $0 \cdot 27 * * *$ & 0.02 & $1.01+\dagger$ & 0.09 \\
\hline $16: 0$ & 9.98 & 0.03 & $13.27^{*}$ & 0.80 & $20 \cdot 25+1$ & $0 \cdot 50$ \\
\hline $16: 1$ & 0.06 & 0.00 & $0.91 *$ & $0 \cdot 10$ & $3.97+t+$ & 0.05 \\
\hline $18: 0$ & $1 \cdot 71$ & 0.01 & $3 \cdot 21^{* *}$ & 0.07 & $5 \cdot 11+t$ & $0-24$ \\
\hline $18: 1$ & $27 \cdot 06$ & 0.02 & $23 \cdot 45^{* *}$ & 0.65 & 22.92 & $0-79$ \\
\hline $18: 2$ & 58.03 & 0.03 & $50 \cdot 02 * *$ & $1 \cdot 14$ & $33 \cdot 02+\dagger \dagger$ & 0.85 \\
\hline $18: 3$ & 1.47 & 0.01 & 1.62 & $0 \cdot 16$ & $0.71+\dagger$ & $0 \cdot 04$ \\
\hline $20: 5$ & ND & & $0.67^{* * *}$ & $0-08$ & $1.62 \dagger$ & $0-31$ \\
\hline $22: 6$ & ND & & $1 \cdot 59 * *$ & 0.25 & 2.57 & $0 \cdot 80$ \\
\hline Minor unidentified & $1 \cdot 69$ & 0.04 & $4.99 * * *$ & 0.04 & $8 \cdot 82+1+$ & $0 \cdot 30$ \\
\hline \multicolumn{7}{|l|}{ Total identified } \\
\hline Saturated & $11 \cdot 69$ & 0.03 & $16 \cdot 75^{* *}$ & $0-87$ & $26 \cdot 37+t+$ & 0.43 \\
\hline Monounsaturated & $27 \cdot 12$ & 0.32 & $24 \cdot 36^{*}$ & 0.70 & 26.89 & 0.75 \\
\hline Polyunsaturated & $59 \cdot 50$ & 0.04 & $53 \cdot 90^{*}$ & 1.36 & $37.92+t+$ & 0.63 \\
\hline$P: S$ & $5 \cdot 09$ & & $3 \cdot 22$ & & 1.44 & \\
\hline
\end{tabular}

ND, not detected ( $<0.2 \mathrm{~g} / 100 \mathrm{~g}$ total fatty acids); $\mathbf{P}: \mathrm{S}$, polyunsaturated:saturated fatty acid ratio. Mean values were significantly different from those for maize oil, $* P<0.05, * * P<0.01, * * * P<0.001$. Mean values were significantly different from those for chylomicrons, $\dagger P<0.05$, $\dagger+P<0.01, \dagger \dagger+P<0.001$. For details of experimental procedures, see pp. $436-439$.

used was chosen because of its use in similar studies (Harris \& Muzio, 1993), for its rapid methylation of fatty acids from triacylglycerols and esterified cholesterol, and because it has been demonstrated to give recoveries of $>99 \%$ for individual saturated and unsaturated fatty acids. Our studies using a mixture of fatty acid standards have confirmed these results.

Significance limits were determined using Student's $t$ test.

\section{RESULTS}

The fatty acid compositions of the different oils and fats used in the present study, together with the compositions of their respective chylomicrons and chylomicron remnants, are shown in Tables 1-5. Palm oil (Table 1) and butter fat (Table 2) contained mainly saturated fatty acids, maize oil (Table 3 ) mainly polyunsaturated, and fish oil (Table 4) approximately equal proportions of saturated, mono- and polyunsaturated fatty acids, while olive oil (Table 5) contained mainly monounsaturated fatty acids. The polyunsaturated: saturated fatty acid (P:S) ratio ranged from 0.03 for butter fat to 5.09 for maize oil, representing a 170 -fold range between the different oils and fat examined.

In olive oil (Table 5), $75 \%$ of the total fatty acid was identified as the monounsaturated fatty acid oleic acid $(18: 1 n-9)$, with the remainder mainly palmitic $(16: 0 ; 11 \%)$ and linoleic acids $(18: 2 n-6 ; 8 \%)$. Palm oil (Table 1$)$ also contained a relatively high proportion of oleic acid $(38.7 \%)$, and a comparable proportion of linoleic acid $(10 \%)$ to that found in 
Table 4. Fatty acid composition of fish oil, and of the chylomicrons and chylomicron remnants derived from it $(\mathrm{g} / 100 \mathrm{~g}$ total fatty acids $) \ddagger$

(Mean values with their standard errors for three independent preparations)

\begin{tabular}{|c|c|c|c|c|c|c|}
\hline \multirow[b]{3}{*}{ Fatty acid } & \multicolumn{6}{|c|}{ Fish oil } \\
\hline & \multicolumn{2}{|c|}{ Oil } & \multicolumn{2}{|c|}{ Chylomicrons } & \multicolumn{2}{|c|}{ Chylomicron remnants } \\
\hline & Mean & $S E$ & Mean & $\mathrm{SE}$ & Mean & $\mathrm{SE}$ \\
\hline $10: 0$ & ND & & ND & & ND & \\
\hline $12: 0$ & ND & & ND & & ND & \\
\hline $14: 0$ & $7 \cdot 52$ & 0.09 & 7.02 & $0 \cdot 33$ & $3 \cdot 04+t+$ & 0.51 \\
\hline $16: 0$ & $19 \cdot 67$ & 0.25 & $17 \cdot 51^{* *}$ & $0 \cdot 40$ & $20 \cdot 11+4$ & $0 \cdot 37$ \\
\hline $16: 1$ & $11 \cdot 86$ & $0 \cdot 17$ & $11 \cdot 26$ & 0.48 & $7 \cdot 65+$ & $0 \cdot 65$ \\
\hline $18: 0$ & 3.84 & 0.04 & $4 \cdot 29$ & $0 \cdot 30$ & $5 \cdot 12$ & 0.53 \\
\hline $18: 1$ & 13.33 & 0.21 & $12 \cdot 32$ & $0 \cdot 10$ & $15 \cdot 69+\dagger$ & 0.63 \\
\hline $18: 2$ & $1 \cdot 16$ & 0.02 & $12 \cdot 72^{* * *}$ & $1 \cdot 43$ & $14 \cdot 89$ & 1.49 \\
\hline $18: 3$ & $1 \cdot 17$ & 0.02 & $1 \cdot 76^{* *}$ & $0 \cdot 10$ & $0.60 \dagger \dagger$ & $0 \cdot 14$ \\
\hline $20: 5$ & $15 \cdot 32$ & 0.08 & $11.98 * * *$ & $0 \cdot 19$ & $12 \cdot 75$ & $1 \cdot 31$ \\
\hline $22: 6$ & $12 \cdot 07$ & $0 \cdot 14$ & $8 \cdot 22 * * *$ & 0.08 & $7.00 \dagger$ & $0 \cdot 36$ \\
\hline Minor unidentified & $14 \cdot 06$ & $1 \cdot 18$ & $12 \cdot 92$ & $0 \cdot 26$ & $12 \cdot 52$ & 0.86 \\
\hline \multicolumn{7}{|l|}{ Total identified } \\
\hline Saturated & $31 \cdot 03$ & 0.46 & 28.82 & $1 \cdot 00$ & $28 \cdot 27$ & $0 \cdot 42$ \\
\hline Monounsaturated & $25 \cdot 19$ & 0.44 & $23 \cdot 58$ & 0.48 & $23 \cdot 34$ & $0 \cdot 33$ \\
\hline Polyunsaturated & $29 \cdot 72$ & 0.23 & $34 \cdot 68^{*}$ & $1 \cdot 58$ & $35 \cdot 24$ & 0.53 \\
\hline$P: S$ & 0.95 & & $1 \cdot 20$ & & $1 \cdot 25$ & \\
\hline
\end{tabular}

$\mathrm{ND}$, not detected $(<0.2 \mathrm{~g} / 100 \mathrm{~g}$ total fatty acids); $\mathrm{P}: \mathrm{S}$, polyunsaturated:saturated fatty acid ratio. Mean values were significantly different from those for fish oil, ${ }^{*} P<0.05,{ }^{* *} P<0.01,{ }^{* * *} P<0.001$. Mean values were significantly different from those for chylomicrons, $\dagger P<0.05,+\dagger P<0 \cdot 01,+\dagger \uparrow P<0.001$. $\$$ For details of experimental procedures, see pp. 436-439.

olive oil ( $8 \%$ ), although the main fatty acid in this oil was palmitic acid (44\%). Palmitic acid was also found to be the main saturated fatty acid in butter fat $(35.1 \%)$, but in contrast to palm oil this represented only $51.2 \%$ of the total saturated fatty acid content, with the remainder comprising the shorter-chain fatty acids myristic (14:0), lauric (12:0), and capric (10:0) acids (Table 2). Maize oil (Table 3) was high in $n-6$ polyunsaturated fatty acids, mainly linoleic acid (58\%), while the menhaden fish oil (Table 4) was relatively enriched in the $n-3$ polyunsaturated fatty acids, eicosapentaenoic acid $(20: 5 n-3 ; 15 \cdot 3 \%)$ and docosahexaenoic acid $(20: 6 n-3 ; 12 \cdot 1 \%)$, and poor in linoleic acid $(1 \cdot 2 \%)$. Oleic and palmitoleic (16:1n-7) acids represented the main monounsaturated fatty acids, and palmitic and myristic acids the main saturated fatty acids in fish oil.

The individual saturated, mono- and polyunsaturated fatty acids present in chylomicrons generally reflected the oils and fats from which they were derived (Tables 1-5), although the proportions of individual fatty acids were altered by the processes of digestion, absorption, and secretion associated with the formation of chylomicrons. When the percentages of saturated, mono- and polyunsaturated fatty acids in chylomicrons were expressed as percentages of those fatty acids in their respective oils and fats, increases in the polyunsaturated fatty acid content of chylomicrons derived from palm oil (1.9-fold), olive oil (2-4-fold), and butter fat (9-5-fold) were found, compared with marginal changes in the composition of maize and fish-oil chylomicrons (Fig. 1(a)). These increases were largely due to an increased content of linoleic acid (1·7-9.3-fold), and to a lesser extent the presence of eicosapentaenoic and docosahexaenoic acids. These $n-3$ fatty acids were present $(0 \cdot 5-2 \cdot 1 \%)$ 
Table 5. Fatty acid composition of olive oil, and of the chylomicrons and chylomicron remnants derived from it $(\mathrm{g} / 100 \mathrm{~g}$ total fatty acids $)+$

(Mean values with their standard errors for three independent preparations)

\begin{tabular}{|c|c|c|c|c|c|c|}
\hline \multirow[b]{3}{*}{ Fatty acid } & \multicolumn{6}{|c|}{ Olive oil } \\
\hline & \multicolumn{2}{|c|}{ Oil } & \multicolumn{2}{|c|}{ Chylomicrons } & \multicolumn{2}{|c|}{ Chylomicron remnants } \\
\hline & Mean & $\mathbf{S E}$ & Mean & $\mathrm{SE}$ & Mean & SE \\
\hline $10: 0$ & ND & & ND & & ND & \\
\hline $12: 0$ & ND & & ND & & ND & \\
\hline $14: 0$ & ND & & 0.48 & 0.19 & 0.89 & $0 \cdot 16$ \\
\hline $16: 0$ & $11 \cdot 24$ & 0.09 & $14 \cdot 39 * *$ & 0.39 & $18 \cdot 53+\dagger \dagger$ & 0.23 \\
\hline $16: 1$ & 0.75 & 0.01 & $1.92 *$ & 0.30 & $3 \cdot 13 \dagger$ & 0.24 \\
\hline $18: 0$ & $2 \cdot 74$ & 0.03 & $4 \cdot 00^{* *}$ & 0.24 & $5.12+\dagger$ & 0.33 \\
\hline $18: 1$ & $75 \cdot 00$ & 0.05 & $53 \cdot 43^{* * *}$ & 1.07 & $46 \cdot 22+\dagger$ & 3.80 \\
\hline $18: 2$ & $8 \cdot 00$ & 0.02 & $16 \cdot 26^{* * *}$ & 0.59 & $18 \cdot 16$ & $1 \cdot 12$ \\
\hline $18: 3$ & 0.56 & $0 \cdot 00$ & $1 \cdot 16^{* * *}$ & 0.05 & $0.71+t$ & 0.06 \\
\hline $20: 5$ & ND & & $0.77^{* * *}$ & 0.07 & $0.79^{11}$ & 0.03 \\
\hline $22: 6$ & ND & & $2 \cdot 12^{* * *}$ & $0 \cdot 11$ & $2 \cdot 62$ & 0.46 \\
\hline Minor unidentified & $1 \cdot 71$ & $0 \cdot 11$ & $5 \cdot 47 * * *$ & $0 \cdot 36$ & 3.83 & $1 \cdot 13$ \\
\hline \multicolumn{7}{|l|}{ Total identified } \\
\hline Saturated & 13.98 & $0 \cdot 14$ & $18 \cdot 87^{* * *}$ & $0 \cdot 50$ & $24.54 t+\dagger$ & 0.36 \\
\hline Monounsaturated & $75 \cdot 75$ & 0.05 & $55 \cdot 35^{* * *}$ & 1.03 & $49 \cdot 35$ & 3.70 \\
\hline Polyunsaturated & $8 \cdot 56$ & 0.02 & $20 \cdot 31^{* * *}$ & 0.69 & $22 \cdot 28$ & 1.04 \\
\hline$P: S$ & 0.61 & & 1.08 & & 0.91 & \\
\hline
\end{tabular}

ND, not detected ( $<0.2 \mathrm{~g} / 100 \mathrm{~g}$ total fatty acids); $\mathrm{P}: \mathrm{S}$, polyunsaturated : saturated fatty acid ratio. Mean values were significantly different from those for olive oil, $* P<0.05$, ${ }^{* *} P<0.01,{ }^{* * *} P<0.001$. Mean values were significantly different from those for chylomicrons, $\dagger P<0.05,+\dagger P<0.01, \dagger \dagger+P<0.001$. $\$$ For details of experimental procedures, see pp. $436-439$.

in all the chylomicrons studied, despite their absence from the corresponding dietary oils and fats, except for fish oil. The content of saturated fatty acids increases during the formation of chylomicrons derived from both maize (1.4-fold) and olive oil (1.5-fold), and the content of monounsaturated fatty acids increased in butter-fat chylomicrons (1-2-fold) (Fig 1(a)). These changes were due to an increased content of palmitic and stearic acids in the case of maize and olive oil chylomicrons, and oleic and palmitoleic acids in the case of butter-fat chylomicrons.

Changes in the proportions of saturated and monounsaturated fatty acids were also observed during chylomicron formation, mainly in the predominant fatty acids found in each of the parent oils and fats. Thus, in olive-oil chylomicrons the oleic acid content was reduced to $71 \%$ of that observed in olive oil (Table 5), and similar reductions were seen in linoleic acid in maize-oil chylomicrons $(86 \%$, Table 3$)$ and in palmitic acid in palm-oil ( $74 \%$, Table 1$)$ and butter-fat $(70 \%$, Table 2$)$ chylomicrons. The contents of the shorterchain fatty acids, lauric and capric acids, predominant only in butter fat, were reduced to $87 \%$ and $36 \%$ respectively, in butter-fat chylomicrons (Table 2). The proportions of eicosapentaenoic $(78 \%)$ and docosahexaenoic acids $(68 \%)$ in fish-oil chylomicrons were also reduced compared with their proportions in fish oil. These changes, and the more marked increases in polyunsaturated fatty acids which occurred during chylomicron formation, were reflected in a very large decrease in the range of the $P: S$ ratios between the different types of chylomicrons, which was 7 -fold compared with 170 -fold for the different dietary oils and fats. 

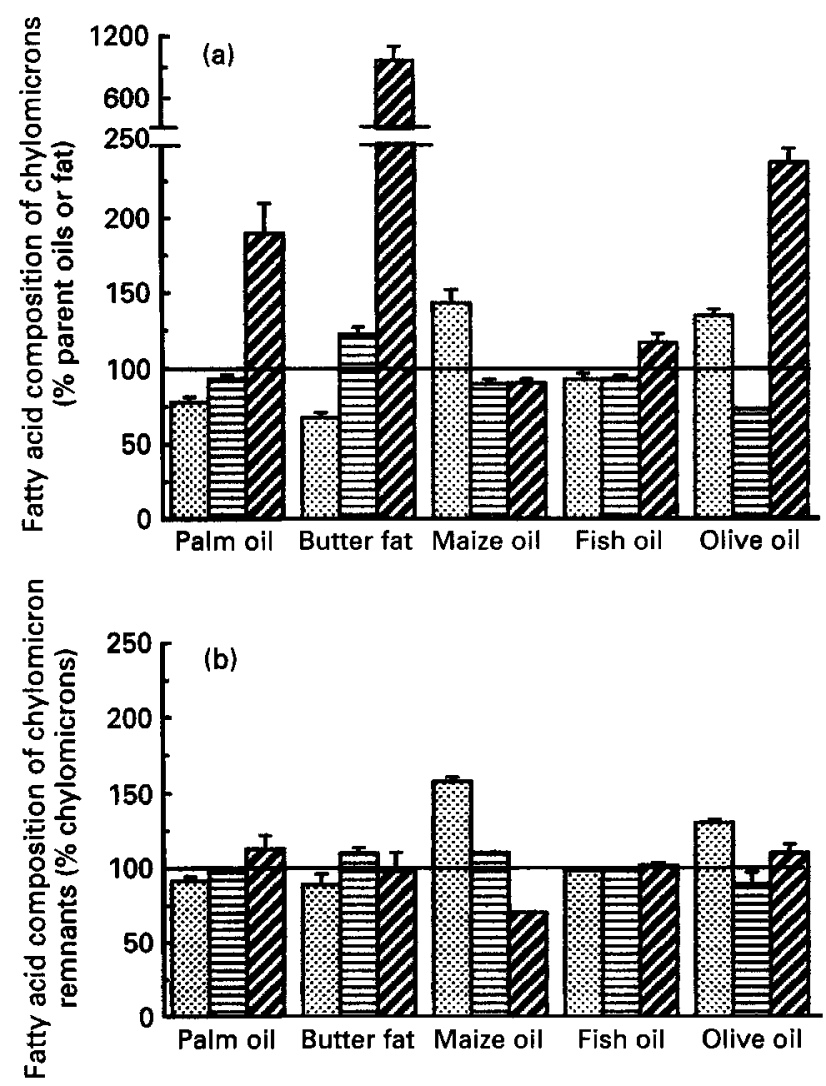

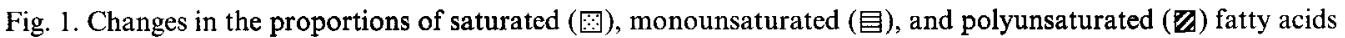
during the formation of chylomicrons and chylomicron remnants from dietary oils and fat. Fatty acid composition of (a) chylomicrons as a percentage of the content of the respective dietary oils and butter fat; (b), chylomicron remnants as a percentage of the content of the respective chylomicrons. Values are means with their standard errors represented by vertical bars for the fatty acid determinations from three separate preparations of chylomicrons and chylomicron remnants. For details of experimental procedures, see pp. 436-439.

The metabolism of chylomicrons to chylomicron remnants resulted in fewer and smaller changes in the proportions of saturated, monounsaturated and polyunsaturated fatty acids than did the formation of chylomicrons from the parent oils (Tables 1-5). The saturated fatty acid content of maize and olive remnants was increased, with a concomitant decrease in polyunsaturated fatty acids in the case of maize oil (Tables 3,5 , Fig. 1(b)). Thus, the range of $P: S$ ratios between the different types of remnants was only $2 \cdot 8$-fold, as compared with 7-fold in the corresponding chylomicrons. The formation of butter fat remnants reduced the proportion of myristic acid to approximately half of that found in the chylomicrons, and 10:0 and 12:0 fatty acids were completely eliminated (Table 2). The proportion of oleic acid in olive-oil remnants was $87 \%$ of that found in the chylomicrons, while the content of palmitic acid showed a small decrease (Table 5). A substantial reduction ( $44 \%$ ) was observed in the linoleic acid content of maize-oil remnants compared with their chylomicrons, and this was accompanied by increases in the proportions of the saturated fatty acids, palmitic and stearic acids (Table 3). The metabolism of fish-oil chylomicrons to chylomicron remnants resulted in decreases in the proportions of myristic and palmitoleic acids and increases in the proportions of palmitic and oleic acids (Table 4). 


\section{DISCUSSION}

The present investigation has demonstrated the acute effects of feeding different dietary oils and fats on the fatty acid composition of their triacylglycerol-rich lipoprotein products, the chylomicrons and chylomicron remnants. The similarity between our analyses of the fatty acid composition of the dietary oils and fats used in the present study and those previously reported (Paul et al. 1980) provides further evidence for the validity of the method of analysis (Morrison \& Smith, 1964) used in this investigation. As this was a study of the effects of fat in the diet on the overall fatty acid composition of the resulting chylomicrons and their remnants, measurements were made on the combined lipid classes. Thus, triacylglycerols, phospholipids, and esterified cholesterols were not separated before analysis. Since triacylglycerol is the predominant class of fatty-acid-containing lipid in chylomicrons ( $90 \%$ by weight) and chylomicron remnants $(80 \%)$ (Redgrave, 1983), the changes in overall fatty acid composition will reflect much more the changes in triacylglycerol composition than those in the other lipids.

Fish oil contained approximately equal proportions of saturated, mono- and polyunsaturated fatty acids, and the resultant chylomicrons contained a similar balanced distribution of fatty acids in their lipids (Table 4, Fig. 1(a)). This observation suggests that in the case of fish oil there are very few losses or gains of fatty acids during the processes of digestion, absorption and re-esterification which result in the formation of chylomicrons. Our observations are compatible with those of Yang \& Kuksis (1991) who used stereospecific analysis and estimated that a maximum of $85 \%$ of the predominant dietary fatty acids in fish oil, i.e. $n-3$ polyunsaturated fatty acids, were retained in 2monoacylglycerols during digestive and absorptive processes associated with chylomicron formation, the greater variation in fatty acid composition being accounted for by the large number of intestinal acyltransferases incorporating fatty acids into chylomicron triacylglycerol in the sn- 1 and sn-3 positions. Thus, it would be expected that the greatest opportunities available for randomization of fatty acids from the pool within intestinal cells would occur in the sn-1 and sn-3 positions.

The fatty acid composition of the other chylomicrons was modified to a greater extent than that of fish-oil chylomicrons compared with the composition of dietary oils and fats from which they were derived. The low proportion of capric acid (10:0) incorporated into butter-fat chylomicrons ( $36 \%$ of that in the parent fat) in our studies is in keeping with the finding that much of the dietary capric acid is absorbed directly into the hepatic portal vein, rather than via the lymphatic system (Pfeffer et al. 1977). In chylomicrons derived from butter fat, palm oil and olive oil, there was an increased proportion of linoleic acid, which tended to increase the chylomicron polyunsaturated fatty acid content to a consistent level of about $20 \%$ of the total fatty acids present. In addition, although there were no $n-320: 5$ and 22:6 polyunsaturated fatty acids in palm oil, butter fat, maize oil or olive oil, there was a minimum of approximately $2 \%$ of these particular fatty acids in all the chylomicrons. Thus, there appears to be a minimal and specific requirement for $n-3$ polyunsaturated fatty acids as well as linoleic acid in the formation of chylomicrons, suggesting another essential role for these particular polyunsaturated fatty acids.

Endogenous fatty acids present in the intestinal enterocytes at the time of fat absorption and during fatty acid esterification by intestinal acyl-coenzyme $A$ transferases would be expected to influence the fatty acid composition of the chylomicrons being formed. By feeding rats with labelled fatty acids, Whyte et al. (1963) demonstrated that unlabelled endogenous fatty acids could represent up to $40 \%$ of the esterified fat in chylomicrons. Therefore, under our experimental conditions it appears that chylomicrons formed from butter fat, low in linoleic acid, are placing much greater demands on the endogenous 
sources of linoleic acid than those formed from olive or palm oil, both of which contain between 8 and $9 \%$ linoleic acid. The sources of these intestinal endogenous fatty acids are not clear, although Shrivastava et al. (1967) demonstrated in fasted rats that the fatty acids liberated from biliary phospholipids in the intestinal lumen represent a major contribution to the fatty acids incorporated into chylomicron lipids. These fatty acids may well be the source of the $n-3$ fatty acids, eicosapentaenoic and docosahexaenoic acids, incorporated into all the chylomicron lipids during their formation from palm, maize, and olive oils and butter fat.

The changes in fatty acid composition associated with the metabolism of chylomicrons to chylomicron remnants were less marked than those observed during chylomicron formation (Fig. 1(b)). This reflects the fact that the metabolism of chylomicrons to chylomicron remnants involves a simple hydrolysis of the chylomicron triacylglycerol core rather than the more complicated partial hydrolysis of dietary triacylglycerols followed by re-esterification which occurs when chylomicrons are formed in enterocytes. However, the proportions of the predominant fatty acids in the different chylomicrons were modified in different ways on conversion to remnants. The percentage of linoleic acid in maize oil remnants was reduced considerably, while that of oleic acid in olive-oil remnants was only decreased by a small amount and the palmitic acid content of palm-oil and butter-fat remnants was not significantly changed (Tables $1,3,5$ ). These results suggest that linoleic acid may be favoured as a substrate for lipoprotein lipase.

Overall, our findings indicate that the changes in fatty acid composition associated with the processes of digestion, absorption and synthesis which occur during the formation of chylomicrons, and subsequently chylomicron remnants, tend to reduce the extremes of fatty acid composition associated with dietary oils and fats. This is mainly due to a decrease in the proportion of the predominant fatty acids and an increase in the proportion of endogenous $n-3$ and $n-6$ polyunsaturated fatty acids. Thus, the range of $P: S$ ratios for the different remnants is reduced to $2 \cdot 8$-fold, compared with 170-fold in the parent oils and fats, with the mean P:S ratio for all the remnants studied being 0.95 . The $P: S$ ratio tends, therefore, to become more balanced during the formation of chylomicron remnants, thereby compensating for the differences in fatty acid composition of different dietary fats. These mechanisms may protect the tissues against sudden changes in the composition of fat in the diet.

The expert technical assistance of Michael Avella and George Stodulski, and the financial support of the British Heart Foundation are greatly appreciated.

\section{REFERENCES}

Ahrens, E. H., Hirsch, J., Insull, W., Tsaltas, T. T., Blomstrad, R. \& Peterson, M. L. (1957). The influence of dietary fats on serum-lipid levels in man. Lancet 1, 943-953.

Bollman, J. L., Cain, J. C. \& Grindley, J. H. (1948). Techniques for the collection of lymph from the liver, small intestine or thoracic duct of the rat. Journal of Laboratory and Clinical Medicine 33, 1349-1352.

Harris, W. S., Conner, W. E. \& McHurry, M. (1983). The comparative reductions of the plasma lipids and lipoproteins by dietary fats: salmon oil versus vegetable oils. Metabolism 32, $179-184$.

Harris, W. S. \& Muzio, F. (1993). Fish oil reduces postprandial triglyceride concentrations without accelerating lipid-emulsion rates. American Journal of Clinical Nutrition 58, 68-74.

Karpe, F., Steiner, G, Uffelman, K., Olivecrona, T. \& Hamsten, A. (1994). Postprandial lipoproteins and the progression of atherosclerosis. Atherosclerosis 109, 82-83.

Keys, A., Anderson, J. T. \& Grande, F. (1965). Serum cholesterol responses to changes in the diet. IV. Particular saturated fatty acids in the diet. Metabolism 14, 776-787.

Kinsell, L. W., Partridge, J., Boling, L., Margen, S. \& Michael, G. (1952). Dietary modification of serum cholesterol and phospholipid levels. Journal of Clinical Endocrinology 12, 909-913.

Mahley, R. W., Hui, D. Y., Innerarity, T. L. \& Beiseigel, U. (1989). Chylomicron remnant metabolism. Role of hepatic receptors in mediating uptake. Arteriosclerosis 9, Suppl. 1, I14-I18. 
Mattson, F. H. \& Grundy, S. M. (1985). Comparison of the effects of dietary saturated, monounsaturated, and polyunsaturated fatty acids on plasma lipids and lipoproteins in man. Journal of Lipid Research 26, 194-202.

Melchior, G. W., Mahley, R. W. \& Buckhold, D. K. (1981). Chylomicron metabolism during dietary-induced hypercholesterolaemia in dogs. Journal of Lipid Research 22, 598-609.

Morrison, W. R. \& Smith, L. M. (1964). Preparation of fatty acid methyl esters and dimethylacetals from lipids with boron fluoride-methanol. Journal of Lipid Research 5, 600-608.

Paul, A. A., Southgate, D. A. T. \& Russell, Y. (1980). McCance and Widdowson's 'The Composition of Foods', Ist Supplement, Amino acids and fatty acids per $100 \mathrm{~g}$ food. London: H.M. Stationery Office.

Pfeffer, P. E., Sampugna, J., Schwartz, D. P. \& Shoolery, J. N. (1977). Analytical ${ }^{13}$ C NMR: detection, quantification and positional analysis of butyrate in butter fat. Lipids 12, 869-871.

Redgrave, T. G. (1970). Formation of cholesteryl ester-rich particulate lipid during metabolism of chylomicrons. Journal of Clinical Investigation 49, 465-471.

Redgrave, T. G. (1983). Formation and metabolism of chylomicrons. International Review of Physiology 28 , $103-130$.

Shrivastava, B. K., Redgrave, T. G. \& Simmonds, W. J. (1967). The source of endogenous lipid in the thoracic duct lymph of fasting rats. Quarterly Journal of Experimental Physiology 52, 305-312.

Whyte, M., Karmen, A. \& Goodman, D. S. (1963). Fatty acid esterification and chylomicron formation during fat absorption. 2. Phospholipids. Journal of Lipid Research 4, 322-329.

Yang, L-Y. \& Kuksis A. (1991). Apparent convergence (at 2-monoacylglycerol level) of phosphatidic acid and 2monoacylglycerol pathways of synthesis of chylomicron triacylglycerol. Journal of Lipid Research 32 , 1173-1186.

Zilversmit, D. B. (1979). Atherogenesis: a postprandial phenomenon. Circulation 60, 473-485. 